\title{
Effects of three repetitive loads of incremental exercise on circulating erythrocytes in Thoroughbred horses
}

\author{
K. Hanzawa' ${ }^{1}$ K. Kubo², M. Kai ${ }^{3}$ A. Hiraga ${ }^{3}$ and S. Watanabe' \\ 'Department of Zootechnical Science, Tokyo University of Agriculture, Tokyo \\ 2Japan Livestock Technology Association, Tokyo \\ ${ }^{3}$ Equine Research Institute, Japan Racing Association, Tokyo
}

\begin{abstract}
Summary
The effects of treadmill exercise on circulating erythrocytes in thoroughbreds were investigated using three 5 -min periods at 5 incremental speeds, ranging from $80 \sim 120 \%$ of the running velocity which produces a blood lactate concentration [La-] of $4 \mathrm{mmol} / \mathrm{l}$ with a 5 -min rest between each period. Mean cell constants and erythrocyte morphology showed no significant changes during repetition of the 3 periods. [La-] was gradually increased by the repeated exercise until it exceeded $2 \mathrm{mmol} / \mathrm{l}$, then suddenly increased. The resting level of osmotic fragility of erythrocytes (OFE) was decreased by the exercise, but the OFE increased with the incremental speeds and had an upward tendency as the exercise intensified. Plasma haptoglobin was not changed, but haemoglobin binding haptoglobin was increased. These results suggest that: 1) the cell volume and shape of the erythrocytes do not cause changes in OFE during exercise;

2) the resting level of OFE is decreased by the repeated exercise; and

3) the anaerobic exercise accelerates the OFE and in vivo haemolysis.
\end{abstract}

Keywords: $\quad$ horse, exercise, erythrocyte, osmotic fragility, VLa4

\begin{abstract}
Effekt von drei wiederholten Belastungen mit steigender Intensität auf zirkulierende Erythrozyten beim Vollblutpferd
In dieser Studie wurde in einem Belastungstest der Einfluß von Laufbandbelastungen auf zirkulierende Erythrozyten bei 3 zweijährigen Vollblütern untersucht. Der Test bestand aus drei Belastungen von je 5 Minuten Dauer. In jeder Belastung wurde die Laufgeschwindigkeit im Abstand von einer Minute erhöht, und zwar von $80 \%$ auf $120 \%$ der Laufgeschwindigkeit, die im Blut eine Laktatkonzentration [La-] von $4 \mathrm{mmol} / \mathrm{l}$ hervorruft (Steigerung nach jeder Minute um 10\%). Zwischen den Belastungen wurde je eine fünfminütige Pause eingelegt. Die mittleren Zellkonstanten (cell constants) und die Morphologie der Erythrozyten zeigten nach den drei wiederholten Belastungen keine signifikanten Veränderungen. Durch die wiederholten Belastungen stieg die [La-] bis zu einer Höhe von 2mmol/l langsam, darüber sehr schnell an. Belastung verminderte die Ruhewerte der osmotischen Fragilität der Erythrozyten (osmotic fragility of erythrocytes; OFE), diese nahm jedoch mit der ansteigenden Geschwindigkeit zu. Wurde die Belastung intensiver, zeigte die OFE eine steigende Tendenz. Die Haptoglobinwerte im Plasma blieben unverändert, jedoch stieg das Haemoglobin-bindende Haptoglobin an. Die Ergebnisse weisen darauf hin, daß: 1) Zellvolumen und Form der Erythrozyten während Belastung nicht die Ursache für Veränderungen der OFE sind. 2) der Ruhewert der OFE durch wiederholte Belastungen erniedrigt wird. 3) anaerobe Belastungen die OFE und die in vivo Hämolyse beschleunigen.
\end{abstract}

Schlüsselwörter: Pferd, Belastung, Erythrozyten, osmotische Fragilität, VLa4

\section{Introduction}

Osmotic fragility of erythrocytes (OFE) from humans is accelerated by exercise, and is an important cause of sports anemia (Davis and Brewer, 1953). Boucher (1989) suggested that the OFE and echinocyte number in peripheral blood of racehorses were increased with exercise by the release of erythrocytes from the spleen into the circulation, while Smith et al. (1989) reported that exercise decreased the OFE and did not change the percentage of red cells as echinocytes. Hanzawa et al. $(1995,1996)$ suggested that the frequent accumulation of erythrocytes in the spleen accelerated the OFE in horses, and that heavy exercise increased the OFE for physical and chemical stresses, particularly accumulation of blood lactate [La-], but that light exercise decreased it, regardless of whether or not erythrocytes were released from the spleen into the circulation. Most authors have used VLa4, the velocity of running, which induces a blood lactate concentration of $4 \mathrm{mmol} / \mathrm{l}$, to evaluate the effect of training or fitness (Persson, 1983; Galloux et al., 1993). Plasma haptoglobin specifically binds to haemoglobin to make a complex $(\mathrm{Hb}-\mathrm{Hp})$. Therefore, the $\mathrm{Hb}-\mathrm{Hp}$ concentration in plasma is increased by intravascular haemolysis (Taira et al., 1992).

The purpose of this study was to determine the effects of repeated loads of incremental exercise on the relationship between OFE and some physiological and morphological properties of erythrocytes in thoroughbred horses.

\section{Materials and methods}

Three 2-year old thoroughbreds, 2 females and 1 male weighing (mean \pm s.e.) $441 \pm 8.8 \mathrm{~kg}$ were used. The horses were conditioned on a treadmill (Mustang-2200, Kagra, Switzerland) 5 times/week for 1 month before the exercise test. The conditioning regimen consisted of prolonged slow-speed exercise at $2-3 \mathrm{~m} / \mathrm{s}$ for approximately $20 \mathrm{~min}$ and a short-duration submaximal exercise at $9-11 \mathrm{~m} / \mathrm{s}$ for $2 \mathrm{~min}$ on a $7 \%$ incline. 
The treadmill velocity for each horse necessary to elicit a blood lactate concentration [La-] of $4 \mathrm{mmol} / \mathrm{l}$ (VLa4) was determined by a preliminary test using the incremental treadmill exercise method;

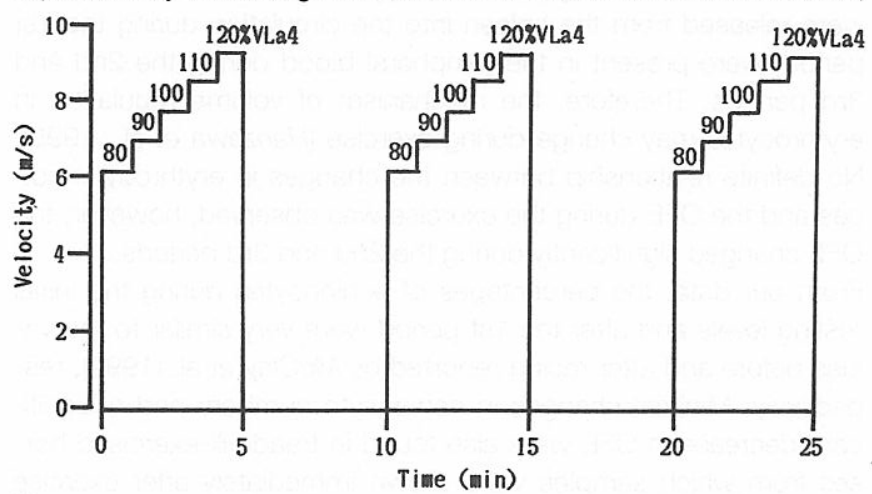

Fig.1: Treadmill program for three repetitions of the incremental exercise.

running speed $1-12 \mathrm{~m} / \mathrm{s}$ at $7 \%$ incline (Galloux et al., 1993). The horses were exercised on the treadmill for three 5-min periods at 5 incremental speeds, ranging from 80 120\% VLa4 with a 5-min rest between each period. Running speed was increased $10 \%$ VLa4 every min (see fig. 1).

Heart rate (HR, bpm) was recorded throughout the study using a commercial heart rate computer (PE-3000, Polar, Finland). Temperature in the core of body (body temperature:BT) was measured using a cardiac output computer (COM-1, American Edwards Laboratory). In all instances, blood samples were obtained from each horse by jugular venepuncture, placed in heparinized test tubes and immediately chilled at $4^{\circ} \mathrm{C}$. An initial resting sample was taken when the horse was relaxed in its stable $30 \mathrm{~min}$ before the start of the exercise. Blood samples during exercise were drawn at predetermined intervals. Following collection, all blood samples were kept on ice until analyzed no longer than $2 \mathrm{hr}$ after sampling. Erythrocyte count (EC, 106/ul), packed cell volume (PCV, \%) and haemoglobin concentration $(\mathrm{Hb}, \mathrm{g} / \mathrm{dl})$ were measured using a Toma-Zeiss blood cell counting plate, a microhaematocrit centrifuge and the cyanmethaemoglobin method, respectively. Mean cell volume (MCV, fl), mean cell haemoglobin $(\mathrm{MCH}, \mathrm{pg})$ and mean cell haemoglobin concentration $(\mathrm{MCHC}, \mathrm{g} / \mathrm{dl}$ ) were calculated from the measured values of $\mathrm{EC}, \mathrm{PCV}$ and $\mathrm{Hb}$.

For accurate evaluation of erythrocyte morphology, one drop of blood within one min after sampling, was dripped directly from a 20 gauge needle into phosphate buffered-saline $(290 \mathrm{mOsmol} / \mathrm{kg})$ containing 1\% glutaraldehyde (Smith et al., 1989). After $14 \mathrm{~h}$ the glutaraldehyde was removed and the cells treated with $0.5 \%$ osmium tetroxide, dehydrated with a series of methanol washes, suspended in propylene glycol and dropped on clean aluminum foil. The aluminum foil was sputter-coated with palladium platinum and viewed in a scanning electron microscope (S-2100B, Hitachi, Japan) for evidence of altered erythrocyte morphology at $\times 10,000$.

Blood lactate [La-] (mmol/l) was measured with an automated lactate analyzer (YSI-1500 Sport, Yellow Springs, USA).

Osmotic fragility of erythrocytes (OFE) was determined by the haemolysis rate $(\mathrm{HL})$ of $50 \mu \mathrm{l}$ of washed erythrocytes in $5 \mathrm{ml}$ of $0.56 \%$ sodium chloride solution (Hanzawa et al., 1995).

Plasma $\mathrm{Hp}$ concentration was assayed using the single radial immunodiffusion (SRID) method (Taira et al., 1992). Anti-equine Hp rabbit serum was made in the authors' laboratory according to the method of Taira et al. (1992). Plasma Hb-Hp was separated by $10 \%$ polyacrylamide gel electrophoresis and was detected by o-dianisidine which stains the peroxidase activity of $\mathrm{Hb}$ (Malin and Baker, 1972). The change in $\mathrm{Hb}-\mathrm{Hp}$ content in plasma was estimated as follows:

[Density of $\mathrm{Hb}-\mathrm{Hp}$ band without addition of $\mathrm{Hb}$ to the plasma] / [Density of $\mathrm{Hb}-\mathrm{Hp}$ band with addition of $\mathrm{Hb}$ to the plasma] $\times[\mathrm{Hp}$ concentration in plasma was measured by SRID method] Variations during experimental exercise were determined by a one way analysis of variance (ANOVA). When the F statistic was significant, multiple comparisons of the means were made using the least significant difference method (LSD). Significant differences between the initial resting level and during the exercise values were analyzed using a paired t test. Differences were considered significant at $P<0.05$. Values are reported as mean \pm s.e.

\section{Results}

The mean of $100 \%$ VLa4 was $7.8( \pm 0.78) \mathrm{m} / \mathrm{s}$. HR was periodically increased by repetition of the incremental exercise, and was more than $190 \mathrm{bpm}$ at 120\% VLa4 (tab. 1). BT was also increased by repeated exercise (tab. 1). Erythrocyte indices are shown in table 1. EC, PCV and $\mathrm{Hb}$ were increased after the 1st period of exercise, and the same levels were maintained during the 2nd and 3rd periods. MCV on 120\% VLa4 during the 1st period was significantly higher than the pre-exercise level, but returned to the initial resting level during the $2 \mathrm{nd}$ and $3 \mathrm{rd}$ periods. $\mathrm{MCH}$ and $\mathrm{MCHC}$ showed no significant changes during the exercise. The mean percentage of red cells circulating as echinocytes (Echi.) was $5.2 \%$ at initial resting levels and $9.1 \%$ after the 1 st period. Their percentages ranged from 5 to $6.3 \%$ during the 2 nd and 3 rd

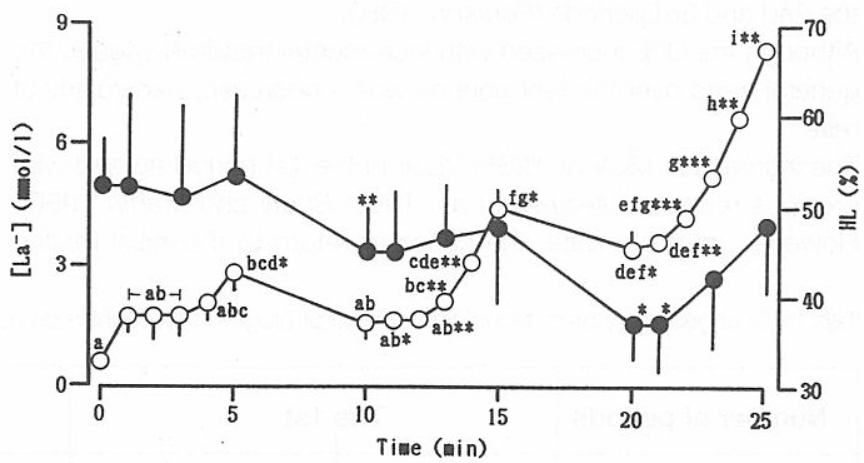

Fig. 2: Changes in blood lactate concentration [La-] (O) and osmotic fragility of erythrocytes (haemolysis rate: $\mathrm{HL}$ in $0.56 \% \mathrm{NaCl}, 0$ ) in thoroughbreds during three repetitions of the incremental exercise.

Differences from each other: $a<b<c<d<e<f<g<h<i$, $\mathrm{P}<0.05$ (LSD).

Differences from pre-exercise: ${ }^{*} P<0.05, \quad{ }^{*} \mathrm{P}<0.01$, ${ }_{* \star *} P<0.001$ (paired $t$ test). Some s.e. values are not visible as they are contained within the symbols.

periods. Rates (\%) of elliptocytes (Ellip., $1.5>$ maximum diameter / minimum diameter) ranged from 5.8 to $9.4 \%$ (tab. 1); these values showed no significant changes during exercise. [La-] was gradually increased by the repeated exercise until it exceeded 2 $\mathrm{mmol} / \mathrm{l}$, then suddenly increased, and its mean value was 8.4 $\mathrm{mmol} / \mathrm{l}$ after the 3rd period (fig. 2). The resting level of OFE was decreased by the repeated exercise, but during each exercise period, OFE increased with the increment in speeds, having an upward tendency as the exercise intensified (fig. 2). As shown in figure 3, plasma Hp remained unchanged during the exercise repetition, while $\mathrm{Hb}-\mathrm{Hp}$ was increased, and all $\mathrm{Hp}$ had changed to $\mathrm{Hb}$ $\mathrm{Hp}$ after the 3rd period (fig. 3). 


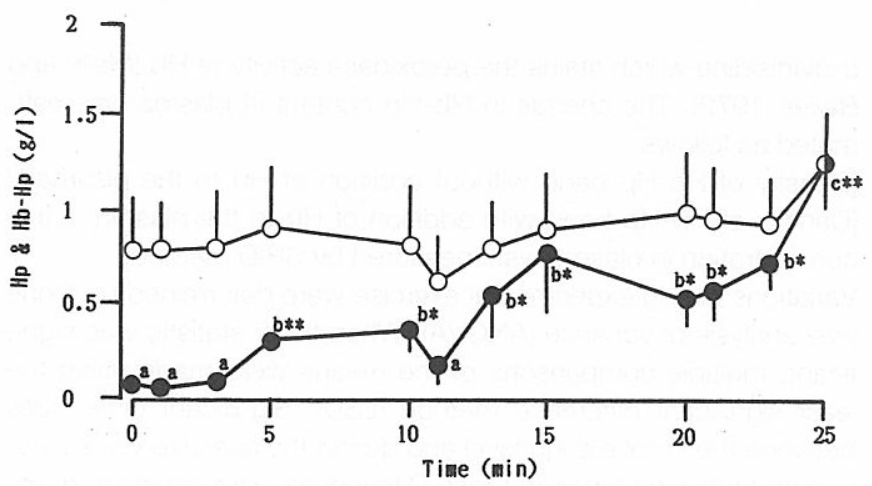

Fig.3: Changes in plasma levels of haptoglobin, $\mathrm{Hp}(\mathrm{O})$ and haemoglobin binding haptoglobin, $\mathrm{Hb}-\mathrm{Hp}(\mathbf{O})$ in thoroughbreds during three repetitions of the incremental exercise. Differences from each other: $a<b<c, P<0.05$ (LSD). Differences from pre-exercise: ${ }^{*} P<0.05$, ${ }^{* *} P<0.01$, ${ }^{* *} P<0.001$ (paired $t$ test). Some s.e. values are not visible as they are contained within the symbols.

\section{Discussion}

The 1st period of $80 \sim 120 \%$ VLa4 was performed at submaximal work levels because HR did not exceed 200 bpm, BT did not exceed $40^{\circ} \mathrm{C}$, and [La-] did not exceed $3 \mathrm{mmol} / \mathrm{l}$ (Bayly et al., 1995; Persson, 1983). However, the total work load became much heavier because the production of lactate passes beyond the oxidation, so a significant increase in BT and [La-] were observed during the 2nd and 3rd periods (Persson, 1983).

Although the OFE increased with incremental treadmill speeds the general trend over the test periods was a decrease, particularly at rest.

The increase in MCV at 120\% VLa4 in the 1st period agreed with previous reports (Hanzawa et al., 1995; Snow and Martin 1990). However, from our data, the cause of return to the initial resting
MCV during the 2nd and 3rd periods is unknown. Changes in the mean cell constants may be related to their release from the spleen (Boucher et al., 1989; Smith et al., 1989). The changes in $\mathrm{EC}, \mathrm{PCV}$ and $\mathrm{Hb}$ during exercise suggest that erythrocytes, which were released from the spleen into the circulation during the 1st period, were present in the peripheral blood during the 2 nd and 3rd periods. Therefore, the mechanism of volume regulation in erythrocytes may change during exercise (Hanzawa et al., 1995). No definite relationship between the changes in erythrocyte indices and the OFE during the exercise was observed, however, the OFE changed significantly during the 2 nd and 3 rd periods.

From our data, the percentages of echinocytes during the initial resting levels and after the 1st period were very similar to the values before and after racing reported by McClay et al. (1992), respectively. Minimal changes in echinocyte numbers and a significant decrease in OFE were also found in treadmill-exercised horses from which samples were drawn immediately after exercise (Smith et al,, 1989). These data indicate that large numbers of echinocytes may not be stored in the spleen of healthy horses. In contrast, it was reported that echinocytes reached $22 \%$ of total red cells during endurance competition (Boucher 1989). Conditions such as electrolyte depletion, increased plasma osmolality, dehydration, or chronic accumulation of metabolic byproducts in horses participating in endurance races may induce echinocyte formation. Weiss et al. (1994) observed that echinocytes were induced by the administration of furosemide, but echinocyte numbers tended to decrease during exercise. We also measured the elliptocyte numbers in this experiment, but this value was not changed by the exercise. Therefore, the deformation of erythrocytes did not cause changes in the OFE during exercise.

In an earlier experiment, [La-] reached $6.5( \pm 1.0) \mathrm{mmol} / \mathrm{l}$ and OFE significantly increased by $38 \%$ from the pre-exercise level after the incremental exercise on a treadmill for about 4 min until the point of fatigue (Hanzawa et al., 1995). After the 3rd period in this experiment, [La-] reached more than $8 \mathrm{mmol} / \mathrm{l}$, but the OFE showed the same level as pre-exercise. This information suggests that accumulation of [La-] is not essential for acceleration of the

Tab.1: Changes in erythrocyte indices and morphology in thoroughbreds during three repetitions of the incremental exercise.

\begin{tabular}{|c|c|c|c|c|c|c|}
\hline \multirow{2}{*}{$\begin{array}{l}\text { Number of periods } \\
\text { Condition }\end{array}$} & \multicolumn{2}{|c|}{ The 1st } & \multicolumn{2}{|c|}{ The 2nd } & \multicolumn{2}{|c|}{ The 3rd } \\
\hline & Rest & $120 \%$ VLa4 & Rest & $120 \%$ VLa 4 & Rest & $120 \%$ VLa4 \\
\hline $\mathrm{HR}(\mathrm{bpm})$ & $31.6 \pm 2.7^{a}$ & $194 \pm 5.6 a$ & $93.2 \pm 3.0^{b^{* * *}}$ & $195 \pm 10^{c * *}$ & $96.9 \pm 3.3^{b^{* * *}}$ & $196 \pm 11^{c * *}$ \\
\hline $\mathrm{BT}\left({ }^{\circ} \mathrm{C}\right)$ & $37.2 \pm 0.29 a$ & $39.9 \pm 0.45^{b *}$ & $38.9 \pm 0.14^{b *}$ & $41.1 \pm 0.42^{c^{* * *}}$ & $39.9 \pm 0.15^{b *}$ & $42.1 \pm 0.46 c^{c *}$ \\
\hline \multicolumn{7}{|l|}{ Erythrocyte indices } \\
\hline $\mathrm{EC}\left(\times 10^{6} / \mu \mathrm{l}\right)$ & $9.4 \pm 0.60^{a}$ & $12.8 \pm 2.0^{b^{*}}$ & $12.4 \pm 0.19^{b^{*}}$ & $13.0 \pm 2.6^{b^{*}}$ & $12.9 \pm 1.0^{\mathrm{b}^{*}}$ & $13.3 \pm 1.6^{b^{*}}$ \\
\hline $\mathrm{PCV}(\%)$ & $39.1 \pm 2.8^{a}$ & $57.4 \pm 1.3^{b^{*}}$ & $53.4 \pm 0.8^{b^{*}}$ & $55.8 \pm 1.1^{\mathrm{b}^{*}}$ & $53.3 \pm 0.89^{\circ}$ & $55.2 \pm 0.95^{b^{*}}$ \\
\hline $\mathrm{Hb}(\mathrm{g} / \mathrm{dl})$ & $14.6 \pm 0.42^{a}$ & $21.3 \pm 1.1^{b^{*}}$ & $19.7 \pm 1.0^{b^{*}}$ & $20.1 \pm 0.77 \mathrm{~b}^{*}$ & $20.0 \pm 0.61^{b^{*}}$ & $20.7 \pm 1.1^{b^{*}}$ \\
\hline $\operatorname{MCV}(\mathrm{fl})$ & $41.6 \pm 0.38^{a}$ & $44.8 \pm 2.7^{b}$ & $43.1 \pm 0.82^{a}$ & $42.9 \pm 3.9^{a}$ & $41.3 \pm 3.9^{a}$ & $41.5 \pm 4.3^{a}$ \\
\hline $\mathrm{MCH}(\mathrm{pg})$ & $15.5 \pm 0.35$ & $16.6 \pm 2.3$ & $15.9 \pm 0.85$ & $15.5 \pm 3.0$ & $15.5 \pm 0.88$ & $15.6 \pm 1.4$ \\
\hline $\mathrm{MCHC}(\mathrm{g} / \mathrm{dl})$ & $37.6 \pm 1.6$ & $37.1 \pm 1.5$ & $38.8 \pm 1.5$ & $36.1 \pm 1.2$ & $37.4 \pm 0.84$ & $37.5 \pm 1.4$ \\
\hline \multicolumn{7}{|c|}{ Erythrocyte morphology } \\
\hline Echi.(\%) & $5.2 \pm 0.7$ & $9.1 \pm 1.6$ & $6.3 \pm 0.62$ & $5.0 \pm 0.7$ & $6.1 \pm 0.66$ & $5.7 \pm 0.82$ \\
\hline Ellip.(\%) & $9.4 \pm 2.4$ & $6.2 \pm 1.0$ & $7.7 \pm 2.1$ & $5.3 \pm 2.2$ & $5.8 \pm 0.86$ & $7.4 \pm 1.6$ \\
\hline
\end{tabular}

levels Differences from each other: $a<b<c, P<0.05$ (LSD).

$0 \quad$ fDifferences from pre-exercise: ${ }^{*} \mathrm{P}<0.05$, ${ }^{* *} \mathrm{P}<0.01$, ${ }^{\star * \star} \mathrm{P}<0.001$ (paired $t$ test). 
OFE during exercise. However, [La-], OFE and $\mathrm{Hb}-\mathrm{Hp}$ increased during incremental exercise in each period, particularly the 3 rd period. Therefore, anaerobic exercise (i.e., glycolysis with lactate accumulation) may accelerate OFE and intravascular haemolysis (Hanzawa et al., 1995, 1996). On the other hand, in our study, increases in OFE and $\mathrm{Hb}-\mathrm{Hp}$ were only observed during incremental exercise periods regardless of [La-] levels, and were not observed at rest between each period. These results suggest that the increase in the physical stress during exercise, i.e., greater rubbing and collision between red cells and the blood vessel wall, and revolution of cells caused by acceleration of blood concentration and blood flow may promote OFE and intravascular haemolysis (Davidson, 1964). OFE showed no significant changes during incremental exercise in the 1 st period, but $\mathrm{Hb}-\mathrm{Hp}$ significantly increased. Therefore, the cause of this increase may be the release of some hemolyzed blood from the spleen into the circulation (Boucher et al., 1989).

Hanzawa et al. $(1995,1996)$ observed that light exercise such as warming-up, cooling-down and continuous trotting reduce the OFE in horses, regardless of whether or not erythrocytes are released from the spleen into the circulation, but the cause of this decrease is unknown. Ventilatory responses of horses to prolonged submaximal exercise on a treadmill was stimulated by an increase in BT, and then blood $\mathrm{pH}$ was significantly increased by hyperventilation (Bayly et al., 1995). In a previous report, the increase in $\mathrm{pH}$ and temperature decreased OFE from several mammals and avian in an in vitro condition (Oyewale, 1992). In our data, HR and BT during rests between the 1st and 2 nd, and the 2 nd and 3rd periods were significantly higher than the pre-exercise levels, and [La-] showed no significant decrease during the rest between each exercise period. These suggest that the stepwise decrease in OFE during rest between each exercise period may be related to the increase in blood $\mathrm{pH}$ promoted by hyperventilation.

Future studies are thus needed in horses to determine the relationship between changes in the OFE and acid-base responses during exercise.

\section{References}

Bayly, W., Schott, H. II and Slocombe, R. (1995): Ventilatory responses of horses to prolonged submaximal exercise. In: Equine Exercise Physiology 4. Eds.: Robinson, N.E. ICEEP, Equine Vet J Suppl. 18, 23-28.

Boucher, J.H. (1989): The role of blood in equine performance. Exercise-induced echinocytosis. In: Equine Sports Medicine. Eds: Jones, W.E., Lea \& Febiger, Philadelphia, 43-52.

Davidson R.J. (1964): Exersional haemoglobinuria. a report on three cases with studies on the haemolytic mechanism. J Clin Pathol 17, 536-540.

Davis J.E. and Brewer, N. (1953): Effect of physical training on blood volume, hemoglobin, alkali reserve and osmotic resistance of erythrocytes. J Appl Physiol 9, 586-591.

Galloux, P., Barrey, E., Valette, J.P., Auvinet, B. and Wolter, R. (1993): Exercise tests in saddle horses. 1: Comparison of step tests on a track and an inclined treadmill. J Equine Vet Sci 13, 417-420.
Hanzawa, K., Kubo, K., Kai, M., Hiraga, A. and Watanabe, S. (1996): Effects of the spleen on changes in osmotic fragility of circulating red blood cells during exercise in thoroughbred horses. In: Proceedings of the 25th World Vet.Cong., J Equine Vet Sci in press.

Hanzawa, K., Kubo, K., Kai, M., Hiraga, A. and Watanabe, S. (1995): Effects of exercise on erythrocytes in normal and splenectomised thoroughbred horses. In: Equine Exercise Physiology 4. Eds.: Robinson, N.E. ICEEP, Equine Vet J Suppl. 18, 439-442.

Malin, S.F. and Baker, R.P.Jr. (1972): Electrophoretic determination of haptoglobin as a hemoglobin complex. Biochem Med 6, 205-209.

McClay C.B., Weiss, D.J., Smith, C.M. and Gordon, B. (1992): Evaluation of hemorheologic variables as implications for exercise-induced pulmonary hemorrhage in racing Thoroughbred. Am J vet Res 53, 1380-1385.

Oyewale, J.O. (1992): Effects of temperature and $\mathrm{pH}$ on osmotic fragility of erythrocytes of the domestic fowl (Gallus domesticus) and guinea-fowl (Numida meleagris). Res Vet Sci 52, 1-4.

Moriyama, H. and Ohhashi, S. (1947): Effect of alkali on osmotic resistance of red blood cells. Igaku to Seibutsugaku (Med \& Biol) 10, 135-138 (in Japanese).

Persson, S.G.B. (1983): Evaluation of exercise tolerance and fitness in the performance horse. In: Equine Exercise Physiology. Eds: Snow, D.H., Persson, S.G.B. and Rose, R.J. ICEEP, Granta Ed., Cambridge, UK. pp. 441-457.

Smith, J.E., Erickson, H.H. and Debowes, R.M. (1989): Changes in circulating equine erythrocytes induced by brief, high-speed exercise. Equine Vet J 21, 444-446.

Snow, D.H. and Martin, V. (1990): Effects of exercise and adrenaline on equine erythrocyte ATP content. Res vet Sci 49, 77-81.

Taira, T., Fujinaga, T., Okumura, M., Yamashita, K., Tsunoda, N. and Mizuno, S. (1992): Equine haptoglobin: isolation, characterization, and the effects of ageing, delivery and inflammation on its serum concentration. J Vet Med Sci 54, 435-442.

Weiss, D.J. Geor, R.J. and Smith, C.M. (1994): Effects of echinocytosis on hemorrheologic values and exercise perfomance in horses. Am J Vet Res 55, 204-210.

K. Hanzawa

S. Watanabe

Department of Zootechnical Science

Tokyo University of Agriculture

1-1-1, Sakuragaoka, Setagaya-ku

Tokyo, 156

Japan

\section{K. Kubo}

Japan Livestock Technology Association

3-9-20, Yushima, Bunkyo-ku

Tokyo, 113

Japan

M. Kai

A. Hiraga

Equine Research Institute

Japan Racing Association

5-27-7, Tsurumaki, Setagaya-ku

Tokyo, 154

Japan 